\title{
Bonding of conventional provisional resin to 3D printed resin: the role of surface treatments and type of repair resins
}

\author{
Na-Kyung Lim, Soo-Yeon Shin* \\ Department of Prosthodontics, College of Dentistry, Dankook University, Cheonan, Republic of Korea
}

\begin{abstract}
PURPOSE. This study evaluated the shear bond strength between 3D printed provisional resin and conventional provisional resin depending on type of conventional provisional resin and different surface treatments of 3D printed resin. MATERIALS AND METHODS. Ninety-six disc-shaped specimens ( $\varnothing 14 \mathrm{~mm} \times 20 \mathrm{~mm}$ thickness) were printed with resin for 3D printing (Nextdent C\&B, Vertex-Dental B. V., Soesterberg, Netherlands). After postprocessing, the specimens were randomly divided into 8 groups $(n=12)$ according to two types of conventional repair resin (methylmethacrylate and bis-acryl composite) and four different surface treatments: no additional treatment, air abrasion, soaking in methylmethacrylate (MMA) monomer, and soaking in MMA monomer after air abrasion. After surface treatment, each repair resin was bonded in cylindrical shape using a silicone mold. Specimens were stored in $37^{\circ} \mathrm{C}$ distilled water for 24 hours. The shear bond strength was measured using a universal testing machine at a crosshead speed of $0.5 \mathrm{~mm} / \mathrm{min}$. Failure modes were analyzed by scanning electron microscope. Statistical analysis was done using one-way ANOVA test and Kruskal-Wallis test $(\alpha=.05)$.

RESULTS. The group repaired with bis-acryl composite without additional surface treatment showed the highest mean shear bond strength. It was significantly higher than all four groups repaired with methylmethacrylate $(P<.05)$. Additional surface treatments, neither mechanical nor chemical, increased the shear bond strength within methylmethacrylate groups and bis-acryl composite groups $(P>.05)$. Failure mode analysis showed that cohesive failure was most frequent in both methylmethacrylate and bis-acryl composite groups. CONCLUSION. Our results suggest that when repairing 3D printed provisional restoration with conventional provisional resin, repair with bis-acryl composite without additional surface treatment is recommended. [J Adv Prosthodont 2020; 12:322-8]
\end{abstract}

KEYWORDS: 3D printing; Provisional restoration; Shear bond strength; Surface treatment

\section{INTRODUCTION}

Computer-aided design/computer-aided manufacturing (CAD/CAM) technology has created a new modality for fabricating provisional prostheses. ${ }^{1}$ On the first visit in clinic, the patient's information is acquired using an intraoral

\footnotetext{
Corresponding author:

Soo-Yeon Shin

Department of Prosthodontics, College of Dentistry, Dankook University, Dandaero 119, Dongnam-gu, Cheonan, Choongnam, 31116, Republic of Korea Tel. +82415500256: e-mail, syshin@dankook.ac.kr

Received June 24, 2020 / Last Revision August 13, 2020 / Accepted

August 24, 2020

(C) 2020 The Korean Academy of Prosthodontics

This is an Open Access article distributed under the terms of the Creative Commons Attribution Non-Commercial License (http://creativecommons. org/licenses/by-nc/4.0) which permits unrestricted non-commercial use, distribution, and reproduction in any medium, provided the original work is properly cited.
}

scanner. Using the CAD program, fabrication of prostheses is easily done, and the saved data allow the clinicians to modify and reproduce the prostheses at any time. Compared to conventional laboratory work, efficiency and predictability for the definitive restoration are also important advantages of the new CAD/CAM methods., ${ }^{2,3}$

There are two methods in fabricating provisional prostheses in CAD/CAM technology: subtractive and additive manufacturing. In subtractive manufacturing, also known as milling, a computer controlled machine cuts away material from a prefabricated block using specific cutting tools. The limitation of this method is that the fabrication of prostheses is affected by the smallest milling tool radius, and thus complex geometries are difficult to reproduce. ${ }^{4}$ Also, used tools show signs of wear after repeated use, which can lead to cracks in the prostheses. ${ }^{5}$ From an ecological view, milling method produces more waste regarding how much is 
used in the final product. ${ }^{6}$

On the other hand, additive manufacturing, also known as 3D printing, creates a 3D object by stacking materials layer upon layer. In contrast to the subtractive method, additive method saves material as it only uses as much the amount as the final product, and is able to produce more complex geometries. Furthermore, 3D printed provisional restorations are known to have sufficient mechanical properties for intraoral use compared to conventionally cured provisional materials. ${ }^{7}$ As a result, this additive manufacturing method, 3D printing, is now a suitable option in fabricating prostheses in the dental field. ${ }^{5}$

Despite the many advantages of 3D printed provisional prostheses, chairside modification is still necessary in clinical practice. Because the provisional crown and bridge are prefabricated before tooth preparation, chairside relining after tooth preparation is required to improve the fit of the margin area. Also, for gradual molding of the soft tissue under ovate pontic, correction of the proximal contact and occlusion based on treatment plan, and repair of the damaged prostheses, adding of conventional provisional resin to $3 \mathrm{D}$ printing resin is inevitable. ${ }^{8}$ Although it would be ideal to remake the provisional restoration, it is economically advantageous to repair it at the chairside. ${ }^{9}$ Provisional resins such as monomethacrylates and dimethacrylates are commonly used for chairside modification. ${ }^{10}$ Although creating a durable bond between the $3 \mathrm{D}$ printed restoration and the conventional repair resin is crucial for its success, limited information is available on the compatibility between two materials.

The aim of this study was to evaluate the shear bond strength between 3D printed provisional resin and conventional provisional resin depending on two types of conventional provisional resin (methylmethacrylate and bis-acryl composite) and four different surface treatments (no additional treatment, air abrasion, soaking in methylmethacrylate
(MMA) monomer, and MMA monomer soaking after air abrasion) of $3 \mathrm{D}$ printed resin. The null hypotheses were that (i) there is no difference in the shear bond strength depending on the type of conventional repair resin and (ii) there is no difference in the shear bond strength depending on different surface treatments of $3 \mathrm{D}$ printed resin.

\section{MATERIALS AND METHODS}

Materials in this study were selected based on usage and long-term verification in clinical practice (Table 1). ${ }^{11} 96$ discshaped specimens of $3 \mathrm{D}$ printing resin were fabricated in size of $20 \mathrm{~mm}$ in diameter and $14 \mathrm{~mm}$ in thickness using a 3D printer (cara Print 4.0, Kulzer, Hanau, Germany) by digital light processing (DLP) method. Specimens were printed in 0 degree angle, where supports were placed on the opposite side of the testing surface. After removing the supports, the specimens were cleaned in distilled water for 20 minutes using an ultrasonic cleaner (SD-120H, Mujigae Co., Seoul, Korea) and dried with oil-free compressed air for $20 \mathrm{sec}-$ onds.

The cleaned specimens were randomly divided into 8 groups of 12 specimens based on 2 types of conventional repair resins and 4 different surface treatments (Table 2). The surface treatments were as follows:

(1) Control: no additional surface treatment.

(2) Air abrasion: air abrasion with $50-\mu \mathrm{m}$ aluminum oxide $\left(\mathrm{Al}_{2} \mathrm{O}_{3}\right)$ particles using an airborne-particle abrasion device (Cobra, Renfert GmbH, Hilzinge, Germany) from a distance of $10 \mathrm{~mm}$, at a pressure of $0.2 \mathrm{MPa}$ for 10 seconds. The specimen was rinsed with water for 10 seconds using a steam cleaner (SESY2014 New Beginning, SEKI Industry, Seoul, Korea) and dried with oil-free compressed air for 10 seconds.

(3) Monomer: specimen was soaked in methylmethacrylate monomer liquid for 60 seconds.

Table 1. Materials experimented in this study

\begin{tabular}{llll}
\hline \multicolumn{2}{c}{ Material } & \multicolumn{1}{c}{ Composition } & \multicolumn{1}{c}{ Manufacturer } \\
\hline 3D printing resin & Nextdent C\&B & Monomethacrylate (Polymethylmethacrylate resin) & Vertex-Dental B. V., Soesterberg, Netherlands \\
& Jet & Methylmethacrylate (Polymethylmethacrylate resin) & Lang, Wheeling, IL, USA \\
Conventional resin & Luxatemp & Dimethacrylate (Bis-acryl composite resin) & DMG, Hamburg, Germany \\
Monomer liquid & Jet & Methylmethacrylate & Lang, Wheeling, IL, USA \\
\hline
\end{tabular}

Table 2. Classification and abbreviations of test groups

Surface treatments

\begin{tabular}{llllll} 
& & Control & Air abrasion & Monomer & Air abrasion + Monomer \\
\hline \multirow{3}{*}{ Type of repair resin } & Jet (methylmethacrylate) & CJ & AJ & MJ & AMJ \\
& Luxatemp (bis-acryl composite) & CL & AL & ML & AML \\
\hline
\end{tabular}


(4) Monomer soaking after air abrasion (Air abrasion + Monomer): air abrasion process was done under the same condition as above. Then, the specimen was soaked in monomer liquid for 60 seconds.

The experiment design is presented in Fig. 1.

One specimen from each surface treatment group was randomly selected for surface examination. The conditioned surfaces of specimens were observed at $\times 500$ and $\times 1000$ magnification using a scanning electron microscope (SEM) (ZEISS GeminiSEM 500, Carl Zeiss Corp., Oberkochen, Germany).
The bonding of conventional provisional resins was performed using a customized silicone mold (Mold master ultra, Molkang, Yangju, Korea) to reduce the error in bonding (Fig. 2). The repair resin was in a cylindrical shape of $2.38 \mathrm{~mm}$ in diameter and $3 \mathrm{~mm}$ in thickness and was left to polymerize at $23^{\circ} \mathrm{C}$ for 60 minutes. The bonded specimens were stored in distilled water at $37^{\circ} \mathrm{C}$ for 24 hours.

Shear bond strength was measured on a universal testing machine (QM100TS, QMESYS, Seoul, Korea). Custom rod was fabricated (Fig. 3) for exact measurement and loaded at the crosshead speed of $0.5 \mathrm{~mm} / \mathrm{min}$ on the bonding inter-

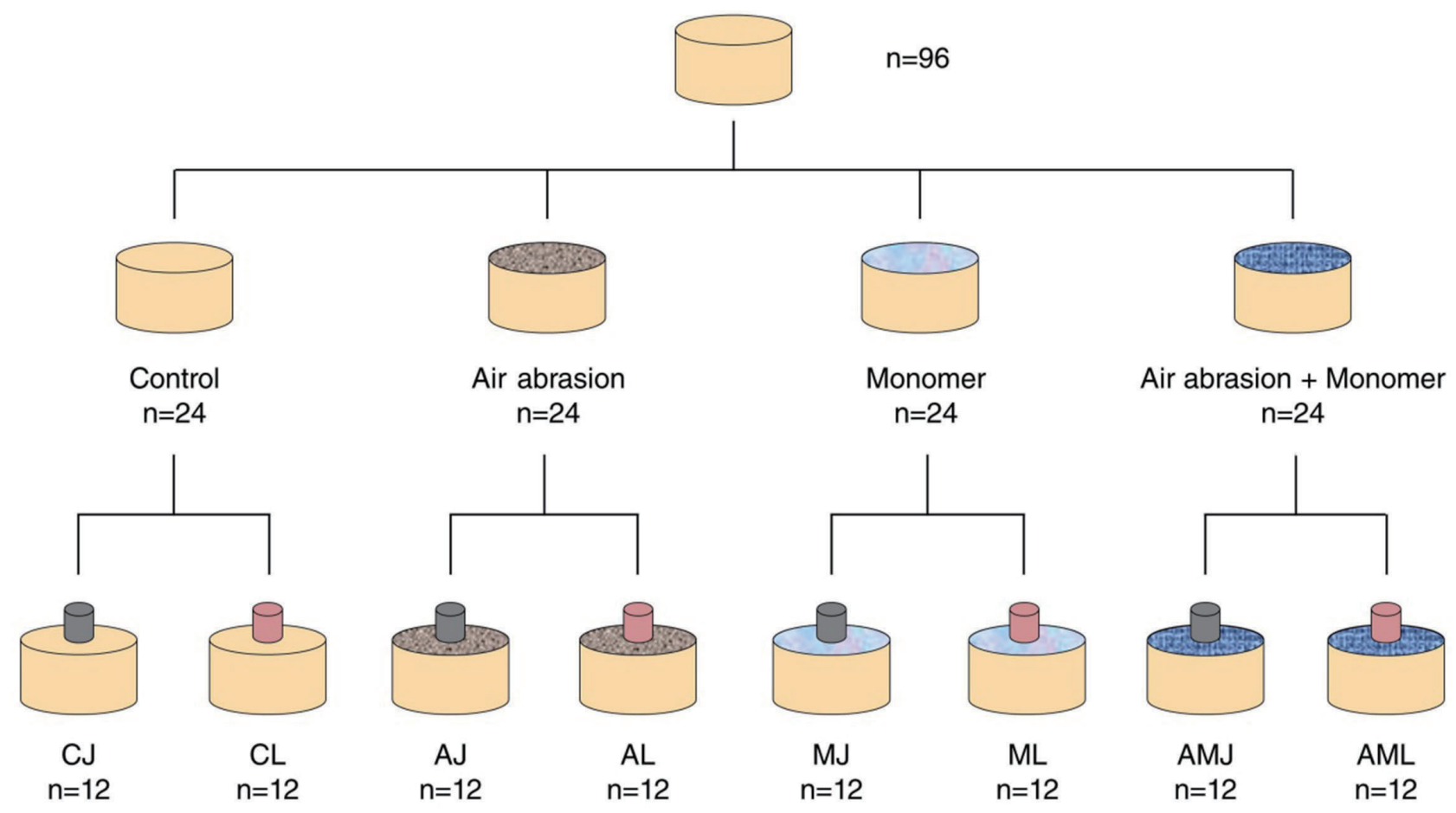

Fig. 1. Experiment design.

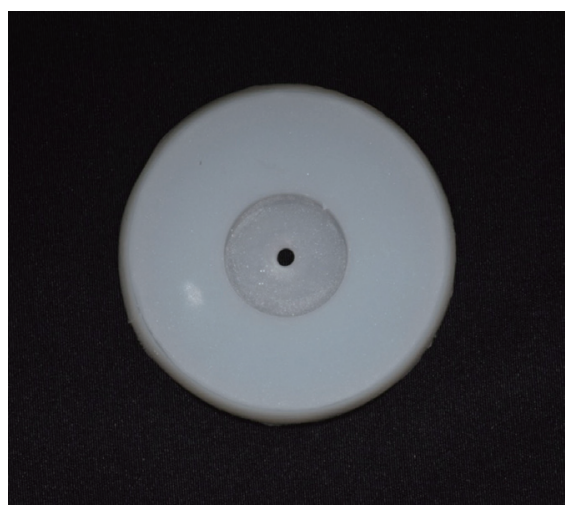

Fig. 2. Silicone mold for bonding conventional resins.

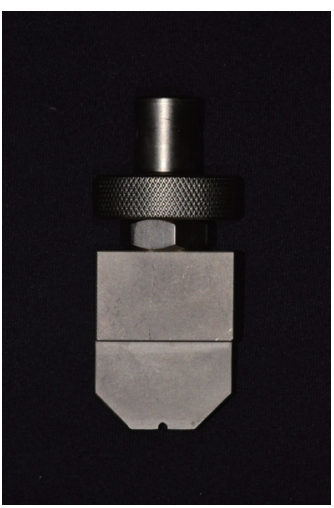

Fig. 3. Customized rod for shear bond strength test. 
face. The maximum load $(\mathrm{N})$ was recorded when fracture occurred. The shear bond strength was calculated by applying the obtained values into the following equation:

$$
\sigma=\mathrm{F} / \mathrm{A}
$$

where $\sigma$ is the bond strength (MPa), $\mathrm{F}$ is the load at failure $(\mathrm{N})$, and $\mathrm{A}$ is the repaired area $\left(\mathrm{mm}^{2}\right)$.

After shear bond strength test, the interfacial fractured surfaces were observed at $\times 50$ magnification using a scanning electron microscope (ZEISS GeminiSEM 500, Carl Zeiss Corp., Oberkochen, Germany). The specimens were classified into 3 groups according to fracture patterns: cohesive failure, adhesive failure, and mixed failure (combination of cohesive and adhesive failure).

The statistical analysis was done using IBM SPSS Statistics v23.0 (IBM Corp., Armonk, NY, USA). Kruskal-Wallis test was performed to assess the effect of different surface treatments on shear bond strength among Jet groups, and one-way ANOVA test for Luxatemp groups. Post hoc test was done using Mann-Whitney U test and Tukey HSD test. The level of statistical significance was set at $5 \%$.

\section{RESULTS}

Table 3 shows the mean and standard deviation of shear bond strength.

When comparing the total mean shear bond strength between Jet and Luxatemp, the total mean of Luxatemp was significantly higher (Table 3). Within Luxatemp groups, group CL showed the highest bond strength and group AML showed the lowest bond strength, but the results showed no statistically significant difference among different surface treatments $(P>.05)$. Within Jet groups, group AJ showed the highest bond strength and group MJ showed the lowest bond strength, but there was also no statistically significant difference among different surface treatments $(P$ $>$.05). When all 8 groups were compared, the shear bond strength of group CL was significantly higher than all of the Jet groups. Group AJ did not show significant difference in bond strength compared to group AL, ML, and AML.

SEM images showed different topographic patterns among specimens (Fig. 4A to $4 \mathrm{H}$ ). The surface of Control group was relatively smooth (Fig. 4A and 4B), whereas Air abrasion group showed roughened surface (Fig. 4C and 4D). The Monomer group showed micro-irregularities (Fig.
4E and 4F) and the Air abrasion + Monomer group showed the roughness more clearly (Fig. $4 \mathrm{G}$ and $4 \mathrm{H}$ ).

SEM images in Fig. 5 represent each failure mode. Failure mode distribution of the experiment groups are shown in Fig. 6. Cohesive failure was the most frequent in both Jet and Luxatemp groups. The percentage of cohesive failure was higher in Luxatemp groups than that of Jet groups. All of the cohesive failures occurred in $3 \mathrm{D}$ printed resin layer, not the repair resin layer.
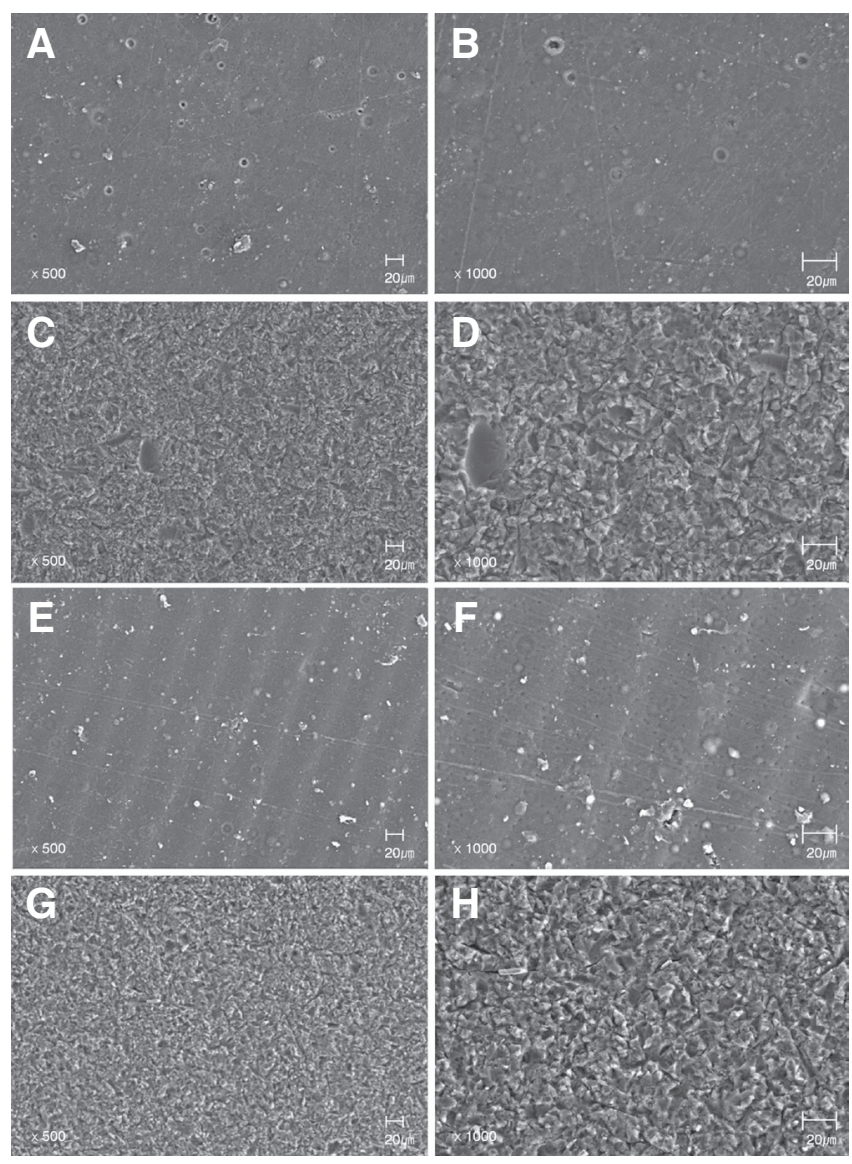

Fig. 4. Scanning electron micrographs of specimens. (A) Control group (magnification $\times 500$ ), (B) Control group (magnification $\times 1000$ ), (C) Air abrasion group (magnification $\times 500$ ), (D) Air abrasion group (magnification $\times$ 1000), (E) Monomer group (magnification $\times 500),(F)$ Monomer group (magnification $\times 1000),(G)$ Air abrasion + Monomer group (magnification $\times 500),(\mathrm{H})$ Air abrasion + Monomer group (magnification $\times 1000)$.

Table 3. Mean and standard deviation of shear bond strengths (unit: MPa)

\begin{tabular}{|c|c|c|c|c|c|}
\hline \multirow{2}{*}{ Materials } & \multicolumn{4}{|c|}{ Surface treatment } & \multirow{2}{*}{$\begin{array}{l}\text { Total } \\
\text { mean }\end{array}$} \\
\hline & Control & Air abrasion & Monomer & Air abrasion + Monomer & \\
\hline Jet & $1.64^{\mathrm{a}}(0.80)$ & $2.07^{\mathrm{ac}}(0.89)$ & $1.45^{\mathrm{a}}(0.50)$ & $1.68^{\mathrm{ad}}(1.08)$ & $1.71(0.84)$ \\
\hline Luxatemp & $2.77^{\mathrm{b}}(0.61)$ & $2.38^{\mathrm{bc}}(0.85)$ & $2.76^{b c}(1.08)$ & $2.25^{\mathrm{bcd}}(0.56)$ & $2.54(0.81)$ \\
\hline
\end{tabular}

Same superscripted letters indicate no significant difference at level of 0.05. 

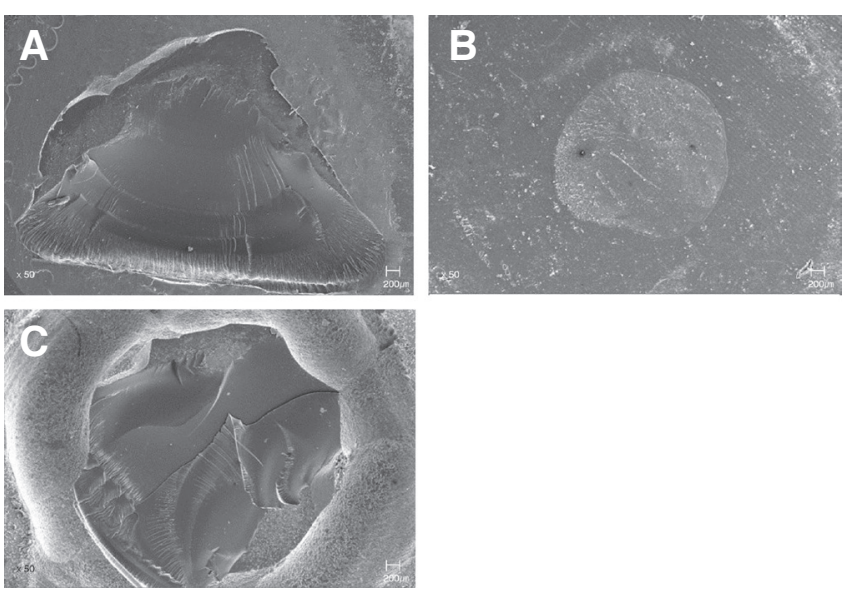

Fig. 5. Scanning electron micrographs of failure modes. (A) Cohesive failure (magnification $\times 50$ ), (B) Adhesive failure (magnification $\times 50$ ), (C) Mixed failure (magnification $\times 50$ ).

\section{A}

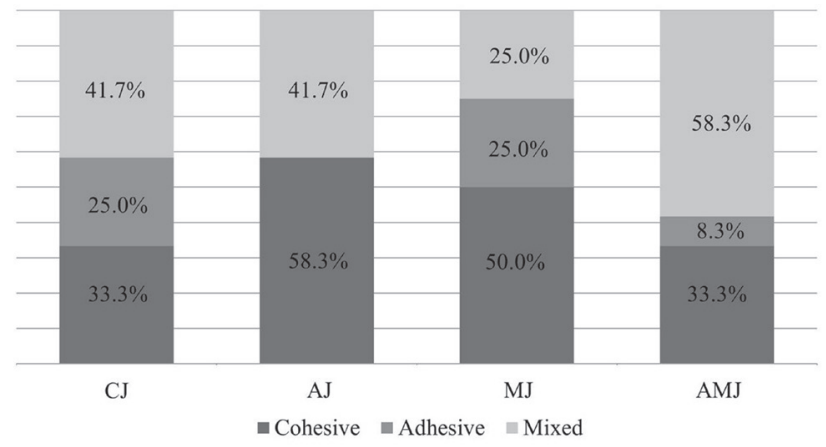

B

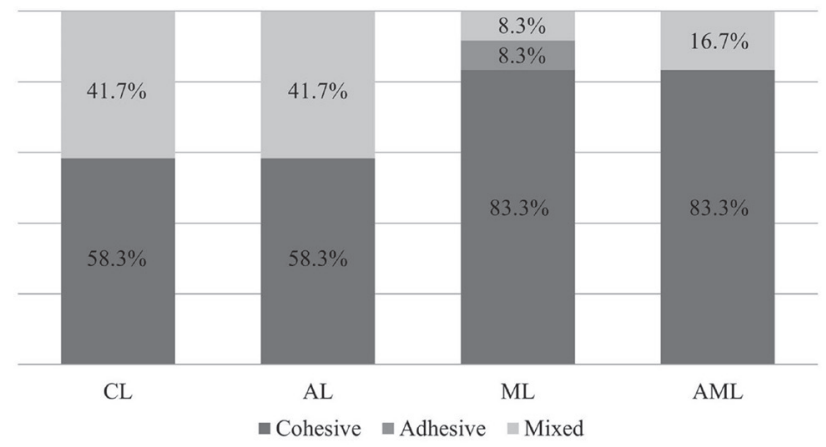

Fig. 6. Failure mode distribution. (A) Jet groups, (B) Luxatemp groups.

CJ: Control Jet, AJ: Air abrasion Jet, MJ: Monomer Jet, AMJ: Air abrasion + Monomer Jet. CL: Control Luxatemp, AL: Air abrasion Luxatemp, ML: Monomer Luxatemp, AML: Air abrasion + Monomer Luxatemp.

\section{DISCUSSION}

The aim of this study was to evaluate the shear bond strength between 3D printed provisional resin and conventional provisional resin depending on (1) the type of conventional provisional resin and (2) different surface treatments. The null hypotheses were that (i) there is no difference in the shear bond strength depending on the type of conventional resin and (ii) there is no difference in the shear bond strength depending on different surface treatments. The first null hypothesis was rejected as the Luxatemp showed better shear bond strength compared to Jet. The second null hypothesis was accepted as there was no statistically significant difference depending on different surface treatments within both Jet and Luxatemp groups.

Measurement of shear bond strength may differ in same material according to the shape of the loading rod. ${ }^{12}$ In the study of Oliveira et al., ${ }^{13}$ shear bond strength of composite resin bonded to enamel surface showed significantly higher value when the width of the shearing blade was smaller. Sinhoreti et al. ${ }^{14}$ also reported that tensions were initially concentrated close to the loading area and then evolved to more complex tensions in the entire system (cleavage effort). Thus in the present study, custom rod was fabricated to match the diameter of bonding specimen for accurate measurement.

Improving the bond strength between two materials involves increasing the surface roughness to promote mechanical retention and application of a bonding agent to promote chemical bonding. ${ }^{11,15-17}$ In the present study, airborne particle abrasion using $50 \mu \mathrm{m}$ Aluminum oxide $\left(\mathrm{Al}_{2} \mathrm{O}_{3}\right)$ was selected for mechanical treatment. To evaluate the sole effect of airborne particle abrasion, other means of mechanical surface treatment, such as polishing or grinding with silicone carbide paper, were excluded. Although Air abrasion groups showed micro-retentive features in SEM images, there was no statistically significant difference in shear bond strength compared to Control groups. This was different from the previous study experimenting with the same 3D printed resin (Nextdent C\&B, Vertex-Dental B. V., Soesterberg, Netherlands). Jeong and $\mathrm{Kim}^{11}$ reported that air abrasion $\left(50 \mu \mathrm{m}\right.$ aluminum oxide $\left(\mathrm{Al}_{2} \mathrm{O}_{3}\right), 10 \mathrm{~mm}$ distance, 10 seconds) after grinding with 220-grit silicon-carbide paper improved the shear bond strength of Luxatemp to $3 \mathrm{D}$ printed resin when compared with the non-treated (control) group. The reason for this difference may be due to additional surface roughness by silicon-carbide paper grinding. Thus in clinical practice, air abrasion alone may be not enough to improve mechanical bonding of repair resin. Furthermore, although specimens of group AJ and AL had the same surface roughness under the same air abrasion condition, group AJ showed improved shear bond strength compared to group CJ, while group AL showed lower shear bond strength compared to group CL. This implies air abrasion may be effective for Jet, but not for Luxatemp. The reason for this difference may be due to (1) the viscosity of the conventional provisional resins or (2) the layered struc- 
ture of the $3 \mathrm{D}$ printed resin. Papacchini et al. ${ }^{18}$ reported that the shear bond strength of repair resin improved when the viscosity decreased due to its ability to flow into the microretentions. Jet showed lower viscosity compared to Luxatemp in this study (Jet was mixed in 4:3 p/l ratio in present study), and thus was able to achieve higher result in Air abrasion group. For another explanation, materials with layered structure may show different bonding behaviors according to different regions within the material, depending on the extent of cross-linking of the resin molecules and the structural layering of the resin. ${ }^{19}$ The exposed surface of $3 \mathrm{D}$ printing resin after air abrasion may show different bonding behaviors to methylmethacrylate and bis-acryl composite resin. Further studies should investigate this difference.

In previous studies, various bonding agents were suggested to promote chemical bonding between CAD/CAM polymethylmethacrylate (PMMA) resin and conventional resin. ${ }^{11,20,21,22}$ Some studies have suggested the use of all-inone bonding agent such as Single bond universal (3M ESPE, St. Paul, MN, USA), but it did not strengthen the bond. ${ }^{11,16,17,23}$ The hydrophilic monomers in the bonding agent, such as HEMA, tend to absorb water and weaken the interfacial bond. ${ }^{11,16}$ Other studies suggested using bonding agents containing methylmethacrylate (MMA) monomer, which significantly improved the shear bond strength compared to the non-pretreated group. ${ }^{20,21,22,24}$ MMA monomers dissolve the surface of CAD/CAM PMMA blank resin, creating free carbon double bonds that form new polymer chains with the repair resin. For this reason, MMA monomer was chosen as the intermediate to promote chemical bonding in this study. Also, it had the advantage of not having to purchase an additional primer for bonding.

By applying MMA monomer, the surface of 3D printed resin was dissolved and swelled. In SEM images of Monomer group, long groove-like-microretentive features were observed. Therefore, it was expected that MMA monomer treated groups may increase the shear bond strength both mechanically and chemically. However, group $\mathrm{MJ}$ and ML did not show significant increase in bond strength compared to group CJ and CL. Unlike CAD/CAM PMMA milling block, 3D printed PMMA resin is a light curing material with bifunctional monomers. Palitsch $e t$ al..$^{25}$ reported that methylmethacrylate does not appropriately copolymerize with the bifunctional monomers of the lightcuring denture base materials, and thus MMA is not an appropriate conditioning liquid. Therefore, MMA may not be an appropriate intermediate for $3 \mathrm{D}$ printed provisional resin. This may also explain why Jet showed lower mean bond strength compared to Luxatemp. Jet contains MMA monomer in its compound, which counteracts with the bonding process to $3 \mathrm{D}$ printed resin.

In failure mode analysis, cohesive failure was the most frequent in both Jet and Luxatemp groups. All of the cohesive failures occurred in 3D printed resin layer. Thus, chairside repair with both Jet and Luxatemp is expected to show satisfactory result in clinical practice. Furthermore, Luxatemp showed more cohesive and less adhesive failures compared to Jet. Therefore, repair with bis-acryl composite will show more reliable bond compared to methylmethacrylate to $3 \mathrm{D}$ printed resin.

In the present study, none of the test methods represented the intraoral environment. Thermocycling may act in two different ways on the bonding behaviors between 3D printing resin and conventional provisional resin. On one hand, it may lead to mechanical stress on the bonding interface, creating cracks and impairment of the bonding. ${ }^{26} \mathrm{On}$ the other hand, thermocycling may increase the shear bond strength by intensifying the process of post-polymerization between 3D printing resin and conventional repair resin. ${ }^{27}$ Further studies should evaluate the effect of long-term aging of the bonded conventional provisional resin to $3 \mathrm{D}$ printed restoration.

\section{CONCLUSION}

Within the limitation of present study, the following conclusions were drawn. Bis-acryl composite resin showed higher shear bond strength to $3 \mathrm{D}$ printed resin compared to methylmethacrylate. Additional surface treatments, neither mechanical nor chemical, increased the shear bond strength between $3 \mathrm{D}$ printed provisional resin and conventional provisional resin. Thus, when repairing $3 \mathrm{D}$ printed provisional restoration with conventional provisional resin, repair with bis-acryl composite without additional surface treatment is recommended.

\section{ORCID}

Na-Kyung Lim https://orcid.org/0000-0003-4178-0982

Soo-Yeon Shin https://orcid.org/0000-0001-6160-7277

\section{REFERENCES}

1. Mainjot AK, Dupont NM, Oudkerk JC, Dewael TY, Sadoun MJ. From artisanal to CAD-CAM blocks: State of the art of indirect composites. J Dent Res 2016;95:487-95.

2. Beuer F, Schweiger J, Edelhoff D. Digital dentistry: an overview of recent developments for CAD/CAM generated restorations. Br Dent J 2008;204:505-11.

3. Gilbert S, Keul C, Roos M, Edelhoff D, Stawarczyk B. Bonding between $\mathrm{CAD} / \mathrm{CAM}$ resin and resin composite cements dependent on bonding agents: three different in vitro test methods. Clin Oral Investig 2016;20:227-36.

4. Strub JR, Rekow ED, Witkowski S. Computer-aided design and fabrication of dental restorations: current systems and future possibilities. J Am Dent Assoc 2006;137:1289-96.

5. Kessler A, Hickel R, Reymus M. 3D Printing in DentistryState of the Art. Oper Dent 2020;45:30-40.

6. van Noort R. The future of dental devices is digital. Dent Mater 2012;28:3-12.

7. Tahayeri A, Morgan M, Fugolin AP, Bompolaki D, Athirasala A, Pfeifer CS, Ferracane JL, Bertassoni LE. 3D printed versus conventionally cured provisional crown and bridge dental materials. Dent Mater 2018;34:192-200. 
8. Burns DR, Beck DA, Nelson SK; Committee on Research in Fixed Prosthodontics of the Academy of Fixed Prosthodontics. A review of selected dental literature on contemporary provisional fixed prosthodontic treatment: report of the Committee on Research in Fixed Prosthodontics of the Academy of Fixed Prosthodontics. J Prosthet Dent 2003;90:474-97.

9. Koumjian JH, Nimmo A. Evaluation of fracture resistance of resins used for provisional restorations. J Prosthet Dent 1990; 64:654-7.

10. Revilla-León M, Meyers MJ, Zandinejad A, Özcan M. A review on chemical composition, mechanical properties, and manufacturing work flow of additively manufactured current polymers for interim dental restorations. J Esthet Restor Dent 2019;31:51-7.

11. Jeong KW, Kim SH. Influence of surface treatments and repair materials on the shear bond strength of CAD/CAM provisional restorations. J Adv Prosthodont 2019;11:95-104.

12. Mondragon E, Söderholm KJ. Shear strength of dentin and dentin bonded composites. J Adhes Dent 2001;3:227-36.

13. Oliveira AC, Oshima HM, Mota EG, Grossi ML. Influence of chisel width on shear bond strength of composite to enamel. Revista Odonto Ciência 2009;24: 19-21.

14. Sinhoreti MA, Consani S, De Goes MF, Sobrinho LC, Knowles JC. Influence of loading types on the shear strength of the dentin-resin interface bonding. J Mater Sci Mater Med 2001; 12:39-44.

15. da Costa TR, Serrano AM, Atman AP, Loguercio AD, Reis A. Durability of composite repair using different surface treatments. J Dent 2012;40:513-21.

16. Ha SR, Kim SH, Lee JB, Han JS and Yeo IS. Improving shear bond strength of temporary crown and fixed dental prosthesis resins by surface treatments. J Mater Sci 2016;51:1463-75.

17. Brosh T, Pilo R, Bichacho N, Blutstein R. Effect of combinations of surface treatments and bonding agents on the bond strength of repaired composites. J Prosthet Dent 1997;77: 122-6.

18. Papacchini F, Magni E, Radovic I, Mazzitelli C, Monticellia F, Goracci C, Polimeni A, Ferrari M. Effect of intermediate agents and pre-heating of repairing resin on composite-repair bonds. Oper Dent 2007;32:363-71.

19. Papazoglou E, Vasilas AI. Shear bond strengths for composite and autopolymerized acrylic resins bonded to acrylic resin denture teeth. J Prosthet Dent 1999;82:573-8.

20. Gilbert S, Keul C, Roos M, Edelhoff D, Stawarczyk B. Bonding between CAD/CAM resin and resin composite cements dependent on bonding agents: three different in vitro test methods. Clin Oral Investig 2016;20:227-36.

21. Bähr N, Keul C, Edelhoff D, Eichberger M, Roos M, Gernet W, Stawarczyk B. Effect of different adhesives combined with two resin composite cements on shear bond strength to polymeric CAD/CAM materials. Dent Mater J 2013;32:492-501.

22. Keul C, Martin A, Wimmer T, Roos M, Gernet W and Stawarczyk B. Tensile bond strength of PMMA- and composite-based CAD/CAM materials to luting cements after different conditioning methods. Inter J Adhe Adhe 2013;46:122-7.

23. Hisamatsu N, Atsuta M, Matsumura H. Effect of silane primers and unfilled resin bonding agents on repair bond strength of a prosthodontic microfilled composite. J Oral Rehabil 2002;29:644-8.

24. Vallittu PK, Lassila VP and Lappalainen R. Wetting the repair surface with methylmethacrylate affects the transverse strength of repaired heat-polymerized resin. J Prosthet Dent 1994;72:639-43.

25. Palitsch A, Hannig M, Ferger P, Balkenhol M. Bonding of acrylic denture teeth to MMA/PMMA and light-curing denture base materials: the role of conditioning liquids. J Dent 2012;40:210-21.

26. Torstenson B, Brännström M. Contraction gap under composite resin restorations: effect of hygroscopic expansion and thermal stress. Oper Dent 1988;13:24-31.

27. Piwowarczyk A, Lauer HC, Sorensen JA. In vitro shear bond strength of cementing agents to fixed prosthodontic restorative materials. J Prosthet Dent 2004;92:265-73. 